\title{
ADDRESSES
}

\section{ANALYSIS AND TESTING OF PREPARED ROOFINGS}

\section{By Herbert Abragam}

Received May 8, 1917

Prepared roofings are composed of one or more layers of fabric impregnated with bituminous matter of relatively soft consistency, which are cemented together and surfaced with layers of bituminous matter of harder consistency. The fabric is ordinarily composed of a fibrous felt, although in certain cases this is used in conjunction with a woven fabric consisting either of burlap or cotton duck.

The bituminous matter may consist either of asphaltic compositions or of coal-tar residues, but these are rarely used together. In this paper, we consider only prepared roofings manufactured from asphaltic compositions.

Prepared roofings are marketed in the form of rolls, usually 36 or 32 in. wide, measuring $108 \mathrm{sq}$. ft. in area, known commercially as a "square," which is sufficient to cover roo sq. $\mathrm{ft}$. of roof surface, allowing for the usual 2 -in. lap at the joints.

It is customary to pack sufficient nails and liquid lap-cement in the core of the roll to affix the roofing to the roof of a building. The rolls are wrapped in paper and headed with metal, paper, or cloth, or a combination of the last two. The heads serve to keep the roll of roofing in shape, and prevent the nails and cement from falling out of the core.

Roll roofings are marketed in various weights known to the trade as "plies." The term "ply," however, is a misnomer, as it does not, as one would suppose, refer to the number of layers of fabric contained in the roofing. It is customary to manufacture the so-called "one-ply" to weigh 35 lbs. gross per square including the paper wrapper, heads, nails and cement in addition to the roofing itself. The net weight of the roofing per square ranges from 2 to $4 \mathrm{lbs}$. less than the gross weight. The gross weight of "two-ply" roofing is $45 \mathrm{lbs}$., and that of "threeply" roofing 55 lbs. per square. Heavier weights are also manufactured, especially in the case of roofings surfaced with moderately coarse or coarse mineral matter, which in certain cases weigh roo lbs. per square or over. At the present time there is no standard practice followed in manufacturing the heavier weights, each manufacturer being guided by his own ideas on the subject.

\section{METHODS OF MANUFACTURE}

In manufacturing prepared roofings, the fibrous felt is first saturated by passing it through a bath of the melted bituminous impregnating material, which soaks into the felt and fills up its pores. The saturated felt may then be coated immediately with the melted bituminous surface coating, while it is still hot, or else it may be wound into large rolls, allowed to cool, and coated later. Both methods are used, one being known as the continuous and the other as the intermittent process of manufacture. Each is claimed to have its particular advantages.

The coated roofing may be wound up in rolls without any further treatment, or it may be sprinkled on the surface with a fine dusting finish of mineral matter to prevent the convolutions of the roll from sticking together in transit or storage. Ground talc, mica and silica are used for this purpose. As they are sprinkled on while the roofing is hot, a certain proportion becomes embedded in the surface coatings and cannot be removed by mechanical means. Most of the dusting finish, however, is detached, and either blows away or else is washed off the roofing by the first rain-storm after it has been applied to a building.
In other cases, moderately coarse to coarse mineral particles are purposely embedded in the surface coating, either to enhance the appearance of the roofing, or else to reduce its cost by making up weight. Popular finishes of this character consist of small rounded grains of sand, coarsely ground particles of talc, angular particles of crushed slate or greenstone (which may either be of a reddish or greenish color), angular particles of feldspar, granite, etc., or even fairly large pebbles or gravel. These are embedded in the surface coating as firmly as possible, so that they may durably attach themselves, and become an integral part of the roofing. In all cases, however, more or less of the mineral particles fail to embed themselves and hence we distinguish between the "detached" and "embedded" mineral matter, the proportions of which serve as a criterion as to the efficiency with which the manufacturing process has been performed.

In some cases it is customary to mix mechanically a certain proportion of finely powdered mineral matter with the surface

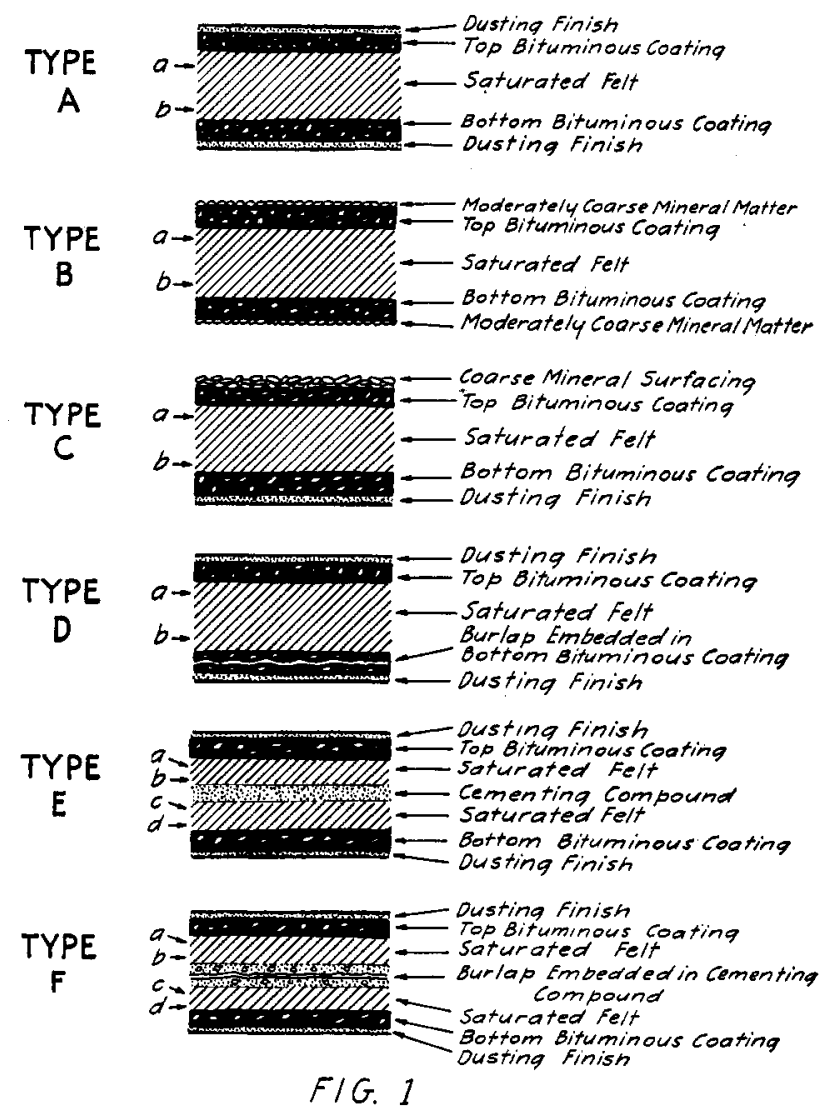

coatings before they are applied to the roofing and while they are still in a molten condition, and for one or more of the following reasons:

(I) To impart a color to the surface coating. For this purpose, bright mineral pigments of various colors are used and intimately mixed throughout a bituminous coating of a special composition.

(2) To increase the weather resistance of the bituminous mixture.

(3) To serve as an extender and reduce the cost of the finished product. 
Where the roofing is composed of more than one sheet of fabric very fine mineral matter may be similarly mechanically mixed with the bituminous layer used to cement them together, for reason (2) or (3).

The various forms of prepared roofing are legion. For all general purposes, however, they may be divided into six types shown in Fig. I.

TYPE A represents a layer of felt saturated and coated with bituminous matter. The surface coatings may be either finished plain or dusted with very fine mineral matter, and they may be either applied smooth and level, or with a veined appearance.

TYPE $B$ is similar to Type A, but surfaced on both sides with moderately coarse mineral matter embedded in the coatings.

TYPE $\mathrm{C}$ is similar to Type $\mathrm{A}$, but surfaced on one side with coarse mineral matter embedded in the coating.

TYPE $D$ is composed of a layer of saturated felt and a layer of burlap or cotton duck cemented together and coated on top and bottom with bituminous matter. It is finished on the surface similar to Type A.

TYPE $\mathrm{E}$ is composed of two layers of saturated felt cemented together and coated with bituminous matter, being finished on the surface similar to Type A.

TYPE $F$ is composed of two layers of saturated felt, cemented together with a layer of burlap in between, and coated with bituminous matter. Its surface is finished as in Type A.

Where burlap is used, it is merely embedded in the bituminous cementing or coating material without previously being saturated, due to the fact that burlap, on account of its structure, will not absorb the bituminous saturation in the same manner as felt.

\section{PHYSICAL TESTS OF THE FINISHED ROOFING}

The original material is tested for pliability, weight, thickness and tensile strength.

Pliability is tested by cutting lengthwise from the center of the roll a strip I in. wide, and commencing with the largest, successively bending it around various cylinders under water at temperatures of 77 and $32^{\circ} \mathrm{F}$., respectively, recording the cylinder on which the surface cracks. Five cylinders are used in the test, measuring $21 / 2,2, I^{1} / 2, I$ and $1 / 2$ centimeter in diameter, respectively. A convenient apparatus for this purpose is shown in Fig. 2. The roofing should be bent parallel to itself, through an arc of $180^{\circ}$, at a uniform speed, and in exactly 2 seconds time.

The pliability is expressed in figures from I to Io, as follows:

\section{Grade Pliability Tests}

1 May be bent through an arc of $180^{\circ}$ in one direction (i. e., flat on itself), and then through an arc of $360^{\circ}$ in the other direction (i. e., flat on itself) without cracking the surface coatings.

2 May be bent flat on itself (i. e., through an arc of $180^{\circ}$ ) without cracking the surface coatings, but will crack when bent through an arc of $360^{\circ}$ in the other direction.

3 Surface cracks when bent through an arc of $180^{\circ}$ (flat on itself).

4 Surface cracks on the $1 / 2-\mathrm{cm}$. cylinder.

5 Surface cracks on the $1-\mathrm{cm}$. cylinder.

6 Surface cracks on the $11 / 2-\mathrm{cm}$. cylinder.

7 Surface cracks on the $2-\mathrm{cm}$. cyilinder.

8 Surface cracks on the $21 / 2-\mathrm{cm}$. cylinder.

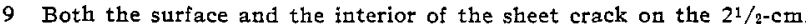
cylinder without, however, cracking entirely through the sheet.

10 The roofing cracks entirely through the sheet on the $2^{1 / 2}-\mathrm{cm}$. cylinder.

Weight, in lbs. per roo sq. $\mathrm{ft}$., is determined in accordance with the method to be described later.

Thickness, in mils (thousandths of an inch), is determined with a micrometer caliper, with flat bearing surfaces about $1 / 2$ in. in diameter.
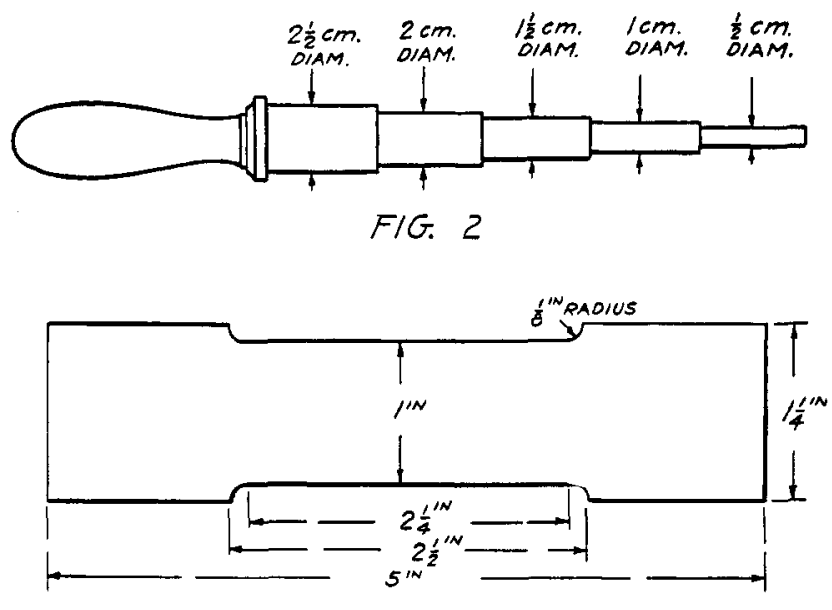

$F / G .3$

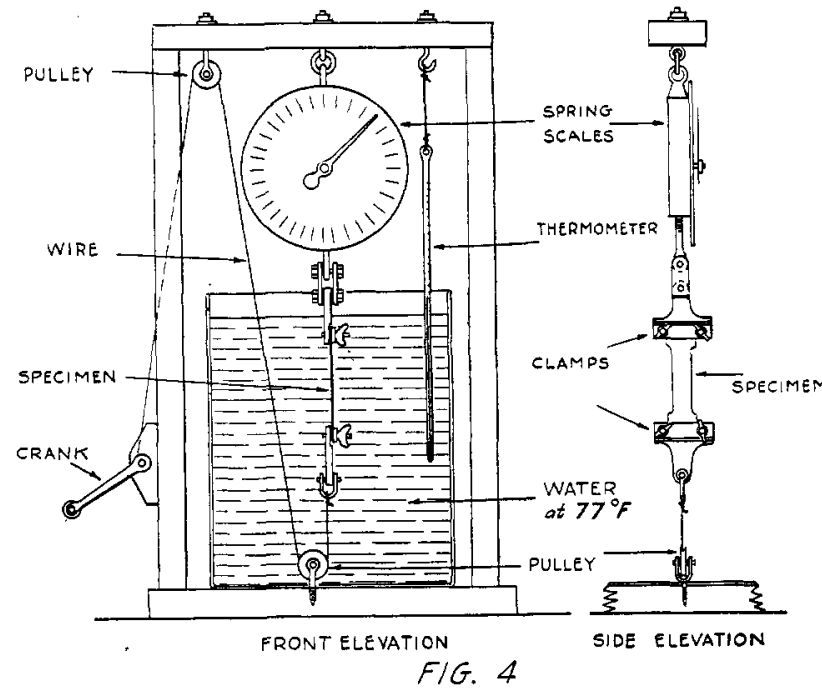

Tensile Strength is determined by subjecting a specimen cut, in the direction of the length of the roll and of the dimensions shown in Fig. 3, to a tension which is increased at a uniform speed of $3 \mathrm{lbs}$. per second, the specimen being maintained at a uniform temperature of $77^{\circ} \mathrm{F}$. during the test. A simple and effective instrument for finding the tensile strength is shown in Fig. 4. Ten such tests are averaged.

\section{HEATING TESTS}

(1) Heating to $125^{\circ} \mathrm{F}$. for $100 \mathrm{Hrs}$. - A strip of the roofing is cut, exactly 12 in. $X 12$ in., care being taken not to disturb any of the detached mineral matter on the surface, and suspended in an oven from a thin wire fastened through holes in the upper edge of the strip. The piece of roofing should be allowed to hang freely and maintained at a temperature of $125^{\circ} \mathrm{F}$. for $100 \mathrm{hrs}$. At the end of this time the roofing is allowed to cool. The pliability, weight, thickness and strength are redetermined and the changes from the original figures expressed in percentages. Any change in the appearance of the surface should also be noted, e. g., sliding of the mineral matter, absorption of the coating by the felt, any yellowing of the surface, blistering, etc.

Heating Test No. I shows the susceptibility of the roofing to the heat of the sun. The loss in weight is equivalent to the volatile matter; a decrease in thickness would indicate that the surface coatings have too low a melting point and are absorbed by the saturant; a large increase in tensile strength and decrease in pliability would indicate that the roofing has a tendency to 
dry out rapidly on exposure to the elements. Any yellowing of the mineral matter on the surface would indicate the presence of unstable oils in the bituminous matter.

(2) Exposure to Air Saturated with Moisture at $77^{\circ} \mathrm{F}$. for 100 Hrs.-Accurately cut a strip of roofing I 8 in. $X$ I 8 in., and weigh. Remove the detached mineral particles from both sides of the sheet with a moderately stiff brush, and reweigh (area equals $2^{1 / 4} \mathrm{sq}$. ft.). Suspend in a tight box containing sufficient water at the bottom to saturate the air with moisture. Cover tightly and allow the specimen to remain in the moist air for Ioo hours at $77^{\circ} \mathrm{F}$. As the moisture enters more readily through the cut edges of the sheet than through the surface itself, 6 in. should be trimmed from the edges at the termination of the test, leaving a strip measuring exactly $\mathrm{I} 2$ in. $X \mathrm{I}_{2}$. in., representing the central portion of the original specimen, and weighing $4 / 9$ ths of the latter. Ascertain the weight, thickness and tensile strength of the I $2 \times 12$ portion at the end of the test, and calculate any variation from the original figures in percentage. The increase in weight should be figured on the basis of the original material including the detached mineral matter.

(3) Immersion in Water at $77^{\circ} \mathrm{F}$. for Ioo Hrs. -This test is run exactly the same as in the preceding, only in this case the specimen should be immersed entirely in water at $77^{\circ} \mathrm{F}$. for 100 hours. An 18 in. $X 18$ in. sheet of roofing should be used in making the test, and this should be trimmed to 12 in. $X 12$ in. before redetermining its weight, thickness or strength.

Heating tests Nos. 2 and 3 show the susceptibility of the roofing to the action of dampness and water.

A skeleton of the physical tests just described is shown in Table I.

\begin{tabular}{|c|c|c|c|}
\hline $\begin{array}{l}\text { Original } \\
\text { Material }\end{array}$ & $\begin{array}{l}\text { After } \\
\text { Heating to } \\
125^{\circ} \mathrm{F} \text {. for } \\
100 \mathrm{hrs} \text {. }\end{array}$ & $\begin{array}{l}\text { After } \\
\text { Exposing to } \\
\text { Air Saturated } \\
\text { with Moist ure } \\
\text { at } 77^{\circ} \mathrm{F} \text {. } \\
\text { for } 100 \mathrm{hrs} \text {. }\end{array}$ & $\begin{array}{l}\text { After } \\
\text { Immersing } \\
\text { in Water } \\
\text { at } 77^{\circ} \mathrm{F} . \\
\text { for } 100 \mathrm{hrs} \text {. }\end{array}$ \\
\hline $\begin{array}{l}\text { Pliability at } 77^{\circ} \mathrm{F} \ldots \ldots \ldots \\
\text { Pliability at } 32^{\circ} \ldots \ldots \ldots\end{array}$ & $\begin{array}{l}P_{1} \\
p_{1}\end{array}$ & $\cdots \cdots$ & $\ldots \ldots$ \\
\hline $\begin{array}{r}\text { Weight in lbs. per } 100 \text { sq. ft. } w \\
\% \text { Decrease in Weight.. } \ldots \\
\% \text { Increase in Weight... } \ldots\end{array}$ & $\begin{array}{l}\frac{w}{w}-w_{1} \\
w\end{array} \times 10$ & $\begin{array}{c}w_{2} \\
\cdots \cdots \\
\frac{w_{2}-w}{w} \times 100\end{array}$ & $\begin{array}{c}w_{3} \\
\cdots \cdots \\
\frac{w_{8}-w}{w} \times 100\end{array}$ \\
\hline $\begin{array}{l}\text { Thickness in Mils........ } t \\
\% \text { Decrease in Thickness } \\
\% \text { Increase in Thickness.. }\end{array}$ & $\begin{array}{l}\frac{t_{1}}{t} \times t_{1} \\
t\end{array} \times 10$ & $\begin{array}{c}t_{2} \\
0 \quad \cdots \cdots \\
\frac{t_{2}-t}{t} \times 100\end{array}$ & $\begin{array}{c}t \\
\cdots \cdots \\
\frac{t_{8}-t}{t} \times 100\end{array}$ \\
\hline $\begin{array}{l}\text { Tensile Strength at } 77^{\circ} \mathrm{F} . \quad s \\
\% \text { Decrease in Strength... .. } \\
\% \text { Increase in Strength... . }\end{array}$ & $\begin{array}{c}s_{1} \\
\cdots \cdots \\
\frac{s_{1}-s}{s} \times 100\end{array}$ & $\begin{array}{l}\frac{s-s_{2}}{s} \times 100 \\
\ldots \ldots\end{array}$ & $\begin{array}{l}\frac{s_{3}}{s} \times 100 \\
\ldots\end{array}$ \\
\hline
\end{tabular}

A variation of these tests consists in first subjecting a specimen of the roofing to the action of moist air or water for Ioo hrs., then drying at $125^{\circ} \mathrm{F}$. for 100 hrs., re-subjecting to the action of moist air or water for another Ioo hrs., and finally repeating the drying process for roo hrs.

Although these tests throw considerable light on the behavior of the roofing towards atmospheric heat and moisture, nevertheless they fail to record one very important factor, namely, the effect of atmospheric oxidation. At the present time we know of no accelerated test by which this can be accurately measured. The effect of oxidation can be recorded only by actually submitting the roofing to an exposure test for a lengthy period of time. This question will be taken up in another paper.
SEPARATING PREPARED ROOFING INTO ITS COMPONENT PARTS

The mineral matter, bituminous matter and fibrous matter present are distributed in the following manner:

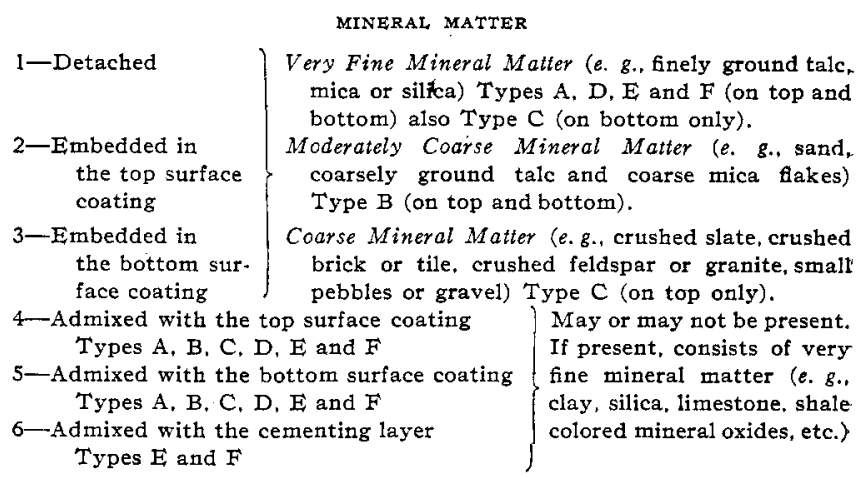

BITUMINOUS MATTER

1-Contained in the top surface coating (all types).

2-Contained in the bottom surface coating (all types)

3 -Contained in the cementing layer (Types $D$ and $F$ ).

4-Contained in the felt present in either one layer (Types A, B, C and D) or distributed in several layers (Types $\mathrm{E}$ and $\mathrm{F}$ ).

\section{FIBROUS MATTER}

1 -One or more layers of felt (all types).

2-Burlap or other fabric (Types $\mathrm{E}$ and $\mathrm{F}$ ).

The separation of prepared roofing into its component parts is carried out as follows:

Weight per IOO Sq. Ft.-Carefully unpack the roll, taking care not to detach any of the mineral surfacing or dusting finish. Weigh the roofing after removing the wrapper, ends, nails and lap-cement packed in the core of the roll. Measure the length and breadth of the roll with a steel tape, recording the dimensions to $1 / 16$ in. Calculate the area in square feet.

Figure the weight of the finished roofing in lbs, per 100 sq. ft...... (1) Cut several stips exactly 3 in. wide across the sheet.

Notk-With roofing 36 in. wide, these strips will measure exactly $3 / 4 \mathrm{sq}$ ft., and with roofing 32 in. wide, they will measure $2 / 3$ sq. ft. Find the weight of each strip in grams.

Calculate the weight of the roofing in lbs. per $100 \mathrm{sq} . \mathrm{ft} . \ldots \ldots \ldots \ldots$ (2) NOTE-With 36 in. roofing, wt. in lbs. per $100 \mathrm{sq}$. ft.

$=0.294 \times$ wt. 3 in. strip in $\mathrm{g}$.

With 32 in. roofing, wt. in lbs. per 100 sc. ft. $=0.331 \times$ wt. 3 in. strip in $g$. Check-Result (1) should equal result (2).

Detached Mineral Matter-Remove the detached mineral particles from both sides of the 3 -in. strips with a moderately stiff brush or cloth and reweigh in grams.

Calculate the weight Detached Mineral Matter in lbs. per 100 sq. ft.... (3)

Dry Felt and Burlap; Total Embedded and Admixed Mineral Matter; Total Bituminous Matter-Extract one of the 3-in. strips in a Soxhlet extractor with benzol. Dry the extracted fabric together with any adhering mineral matter at $I I 0^{\circ} \mathrm{C}$. Cool in a desiccator and weigh the felt as rapidly as possible before it has an opportunity to absorb moisture from the air. Repeat the drying, until the weight is constant. Carefully brush off, weigh and set aside the adhering mineral matter.

Calculate the weight of each layer dry felt or burlap in lbs. per 100 sq. ft. (4)

NoTE-Use the separated felt or burlap for examining its physical and chemical characteristics according to the methods described later.

Separate the mineral matter from the benzol extract by filtering or centrifuging, wash clean with successive portions of benzol, dry and weigh. Combine with the mineral matter brushed off the extracted felt.

Calculate the weight of the total embedded and admixed mineral matter in lbs. per 100 sq. ft...................... 
Screen through a set of standard sieves of different mesh. A mere inspection of the particles retained by the various screens will enable one to separate the moderately coarse or coarse embedded mineral matter from any very fine admixed mineral matter present in Types B and C.

Calculate the weight of moderately coarse or coarse embedded mineral matter in lbs, per $100 \mathrm{sq}$. $\mathrm{ft}$. for Types $\mathrm{B}$ and $\mathrm{C}$.

Calculate the combined weights of very fine embedded mineral matter and admixed mineral matter in $1 \mathrm{bs}$, per $100 \mathrm{sq}$. ft. for Types $A$,

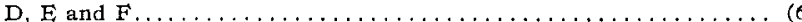

Calculate the total weight of bituminoụs matter in 1 bs. per 100 sq. ft.,

i. e., [1] $-[(3)+(4)+(5)] \ldots \ldots \ldots \ldots \ldots \ldots \ldots \ldots \ldots \ldots$ (7)

Bituminous Saturation in the Felt-Warm a strip about 2 in. wide cut lengthwise from the roll, and tear off the coatings as shown in Fig. 5, taking care that in so doing as little as possible of the saturated felt is removed with the coatings, and, on the other hand, that none of the coatings or cementing layer remains adhering to the strip of saturated felt. The small arrows to the left of the various types of roofing illustrated in Fig. I indicate approximately where the layers should be separated. This can readily be accomplished with a little practice and dexterity. Where the roofing is composed of one layer of felt. as in Types A, B, C and D, the zone between the arrows $a$ and $b$ should be separated. Where the roofing is composed of two layers of felt, as in Types $\mathrm{E}$ and $\mathrm{F}$, separate the zones between the arrows $a$ and $b$, also $c$ and $d$, respectively. In this manner, about $25 \mathrm{~g}$. of the saturated felt (free from the coating or cementing layers) are obtained from each layer. Weigh and extract each portion separately in a Soxhlet with benzol. Dry

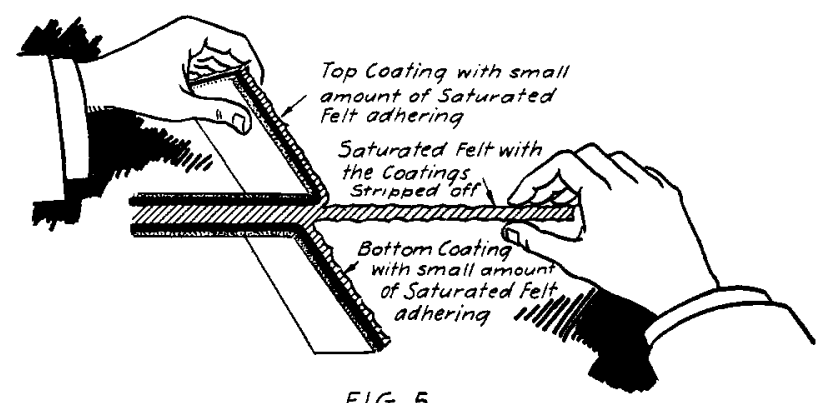

FIG. 5

the extracted felt at I $^{\circ} 0^{\circ} \mathrm{C}$. to constant weight, desiccate and weigh. Calculate the weight of bituminous saturation by difference, and evaporate the benzol extract to exactly this weight.

NOTE-Use the residue of bituminous saturation recovered from each layer of felt for examining its physical and chemical characteristics, according to the methods described later.

Calculate the per cent of bituminous saturation carried by each layer

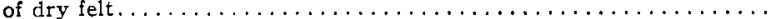

Calculate the weight of bituminous saturation present in each layer

of the felt in lbs. per $100 \mathrm{sq}$. ft. $[i . e .,(8) \times(4)] \ldots \ldots \ldots \ldots \ldots \ldots$ (9)

Weights of Bituminous Matter in the Coatings and Cementing Layer-TYPES A, B, C AND D-The combined weights of bituminous matter in the top and bottom coatings expressed in lbs. per IoO sq. ft. may be calculated by subtracting ( 9 ) from (7).

To find the respective weights of bituminous matter in the top and bottom surface coatings, take a 3 -in. strip cut across the sheet of roofing, from which the detached mineral matter has been removed, and split it lengthwise by tearing the felt midway between the points $a$ and $b$ (Fig. I). Weigh and extract each section separately in a Soxhlet. Desiccate and weigh the dry felt in each section (and the burlap in Type D), also separate an 1 weigh the total embedded and admixed mineral matter. Calculate the weight of bituminous saturation present $[i . e$, weight of dry felt $\times(8)]$. From the original weight of each section subtract the combined weights of dry felt, bituminous saturation, embedded and admixed mineral matter. The difference represents the weight of bituminous matter in the surface coating carried by that particular section.

Calculate the weights of bituminous matter in the top and bottom coats, respectively, in lbs. per 100 sq. ft................ (10)

IN TYPES E AND F-Take a 3 -in. strip freed from the detached mineral matter as previously described, and split it into three sections, by tearing through the felt midway between the points $a$ and $b$, also $c$ and $d$, respectively (Fig I). Weigh and extract each of the three sections separately in a Soxhlet. Separate, and in each case weigh the dry felt (also the burlap in Type F), and the total mineral matter. Following the method previously described:

Calculate weights of bituminous matter in the top and bottom coats respectively in lbs. per 100 sq. ft..................... (11)

Calculate weight of bituminous matter in the cementing layer in lbs. per 100 sq. $\mathrm{ft}$.

Calculate weight of very fine mineral matter admixed with the cementing layer in lbs. per $100 \mathrm{sq} . \mathrm{ft}$.

Very fine Embedded Mineral Matter also admixed Mineral Matter, in the Top and Bottom Coatings, respectively-TYPES A, D, E AND FTake another 3 -in. strip from which the detached mineral matter has been brushed off, and remove the outer layer of the top and bottom coatings, respectively, by means of moderately rough sand paper. Enough of the surface should be scraped to remove every vestige of the very fine embedded mineral matter, and at the same time care should be taken not to cut

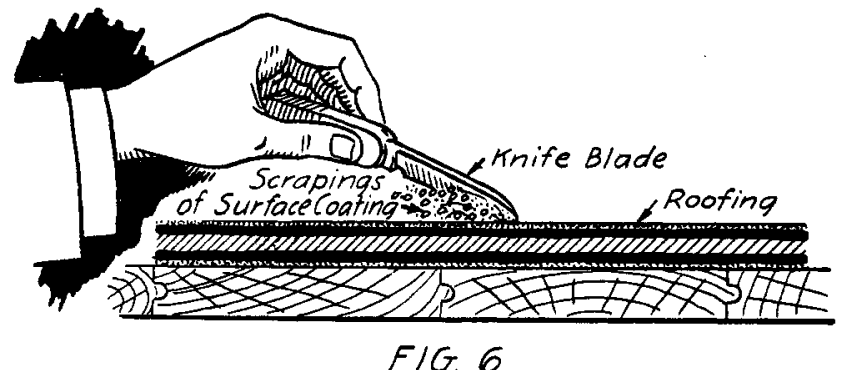

completely through the surface coatings into the saturated felt underneath.

With Types A and D, split the scraped sheets lengthwise, midway between the points $a$ and $b$. With Types $E$ and $F$, split the scraped sheets lengthwise midway, respectively, between the points $a$ and $b$, also $c$ and $d$, discarding the central section. Extract the scraped outer sections separately with benzol, as before, recovering and weighing:

The dry felt present in the respective scraped sections.......... (12)

The admixed mineral matter present in the scraped sections ......... (13)

The total bituminous matter present in the surface coating and sat-

urating the felt in the respective scraped sections............. (14)

The dry burlap (in Type D).

Calculate the bituminous matter present in the felt in the respective

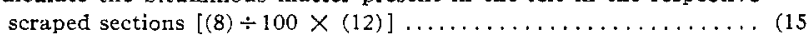

Hence the bituminous matter present in the surface coating remaining on the respective scraped sections $=(14)-(15) \ldots \ldots \ldots \ldots \ldots \ldots$ (16)

The proportion of very fine mineral matter admixed with the bituminous matter in each coating $=(13) \div(16) \ldots \ldots \ldots \ldots \ldots$ (17)

Total weight of very fitse mineral matter admixed with the respective coatings in lbs. per $100 \mathrm{sq}$. ft. $=(17) \times(10)$ [in Types $A$ and $D$ ] or $(17) \times(11)$ [in Types $E$ and F $\ldots \ldots \ldots \ldots \ldots \ldots \ldots \ldots$ And weight of very fine mineral matter embedded in the surface of the respective coatings in lbs. per $100 \mathrm{sq} . \mathrm{ft} .=(6)-(18)$

Nature of the Bituminous Matter in the Coatings and Cementing Layer-Brush off the detached mineral matter from a surface about 2 sq. ft. in area. Then scrape off the outer portion of the 
surface coating with a sharp knife. This is accomplished by holding the knife at right angles to the sheet of roofing resting on a firm, level surface, and rapidly drawing the blade sideways under moderate pressure (Fig. 6). Care should be taken to avoid scraping entirely through the surface coating. This is important. Weigh the scrapings, and then dissolve in benzol. Separate the mineral matter by filtering or centrifugating, and wash with successive portions of benzol. Dry and weigh the mineral matter. Calculate the weight of bituminous matter in the scrapings by difference, and evaporate the combined benzol extracts on the water bath to exactly this weight, completing the evaporation if necessary in an oven. Both surface coatings should be treated separately in this manner. In Type $\mathrm{D}$ the bottom coating can readily be removed by cooling the specimen in an ice-chest and rapidly tearing off the burlap, which will carry most of the bottom coat with it. This should be extracted, filtered and the extract evaporated to obtain the pure bituminous matter present.

With Type $F$ the central web of burlap can be torn out, and the bituminous matter contained in the cementing layer separated in the same manner.

With Type $E$ the bituminous matter can be separated from the cementing layer between the sheets of felt, by cooling in an ice-chest, rapidly tearing the specimen in two along the plane of the cementing layer, scraping and separating the bituminous matter as described for the surface coatings.

Use the residues of bituminous matter for examining their physical and chemical characteristics.

\section{TESTING THE RAW FELT}

$A s h$-The ash is determined by incineration and expressed in percentage.

Fibers Present-The percentage composition of the fibers is determined microscopically by staining them with a solution of zinc-chlor-iodide (composed of $20 \mathrm{~g}$. of zinc chloride dissolved in $12 \mathrm{cc}$. of water to which is then added $4 \mathrm{~g}$. of potassium iodide and $O . I \mathrm{~g}$. of iodine), and counting under a microscope having a magnification of about Ioo diameters. The individual fibers are recognized by their characteristic shapes and the colors to which they are stained by the zincchlor-iodide solution. The percentages are ascertained by counting the fibers in a number of fields and finding their average. The following classes of fibers are reported:

$$
\begin{aligned}
\text { Rag Fibers }\left\{\begin{array}{l}
\text { Cotton fibers-stained wine-red } \\
\text { Wool fibers-unstained by the solution } \\
\text { Jute and manila fibers-stained a yellowish brown }
\end{array}\right. \\
\text { Paper Fibers }\left\{\begin{array}{l}
\text { Mechanical wood pulp-stained lemon-yellow } \\
\text { Chemical wood pulp-stained grayish purple } \\
\text { to purple }
\end{array}\right.
\end{aligned}
$$

"Number"-This is an arbitrary figure adopted by the trade, corresponding to the weight in pounds of a ream consisting of 480 sheets, each measuring I $_{2}$ in. $X$ I 2 in.

Thickness-This is expressed in mils.

Mullen Strength--Since the raw felt is not susceptible to changes in temperature (as is the case with the finished roofing) it may be tested for tensile strength by means of the Mullen tester. The specimen is accordingly tested at room temperature by increasing the tension at a uniform speed of $2 \mathrm{lbs}$. per second until it ruptures.

Thickness Factor-This is equal to the thickness in mils divided by the "number" of the felt.

Strength Factor-This is equal to the Mullen strength in pounds divided by the "number" of the felt.

\section{TESTING THE RAW BURLAP OR DUCK}

Weight-In the case of burlap and cotton duck, the weight is figured in ounces per square yard, which is the customary way of designating these.

Thickness-Expressed in mils.

Mullen Strength-Determined as described for testing the raw felt.

\section{BITUMINOUS COATING, SATURATION AND CEMENTING COMPOUNDS}

These should be examined by means of the following tests:

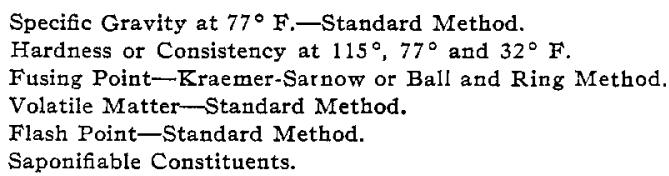

\section{MINERAL SURFACING AND ADMIXED MINERAL MATTER}

These should be subjected to a granularmetric analysis by passing them through a set of sieves and finding the percentage retained on the various sieves. Further knowledge can be gained regarding the character of the mineral matter, where required, by subjecting it to a quantitative analysis.

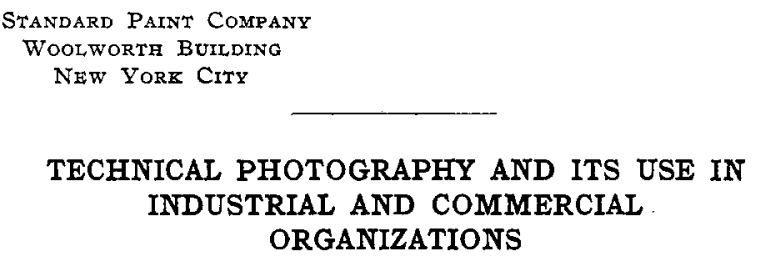

\section{TECHNICAL PHOTOGRAPHY AND ITS USE IN ORGANIZATIONS} INDUSTRIAL AND COMMERCIAL

By JohN H. GRAFr'

It is not the aim of this paper to discuss the different technical manipulations of photography, but to illustrate how photography can be used technically for better efficiency and to good advantage in science, engineering, industry, and commerce, and how it is needed not only in big corporations or large engineering or research laboratories, but how practically no concern is so small that it can afford to be without photography in one form or another. With the exception of a very few large concerns that had some sort of photographic department for the sake of photographing salesmen's samples, etc., there was until very recently no concern that had installed a photographic department as a unit in their business-a photographic department whose first and foremost duty it was to serve all the other departments and the company as a whole; the writer believes himself to be one of the first in this line. He installed such a department in one of the larger concerns of the country for the sake of efficiency in each and all of the departments, and the photographic department of this concern to-day serves over fifty different departments of the corporation, so that what was a dream three years ago is to-day a necessity which none of the departments could be without.

It is clear that to serve fifty different departments efficiently, many technical problems must be solved, and the manager of the new department must not only be a photographer in the fullest sense of the word, but also must have a general knowledge of drawing, engineering in its different branches, elementary chemistry and physics, microscopy, business management, buying, selling and advertising-in other words technical photography. Embracing all this, the writer hopes to see some day the "Photographical Engineer," who has had fundamental practical and theoretical college training for this purpose.

How, then, can technical photography be used in an industrial

1 Technicai Photographer of the Berlin Mills Co., Berlin, N. H. 